\title{
Effect of an Er,Cr:YSGG Laser on the Debonding of Lithium Disilicate Veneers With Four Different Thicknesses
}

\author{
Hernán Giraldo Cifuentes ${ }^{1 *}$, Juliana Castaño Gómez², Angela Natalia López Guerrero² ${ }^{2}$ Johanna Muñoz ${ }^{2}$ \\ 1 Prosthodontics Department - Director, Fundación Universitaria CIEO - UNICIEO \\ ${ }^{2}$ Oral Rehabilitation -Student, Fundación Universitaria CIEO - UNICIEO
}

\author{
*Correspondence to \\ Hernán Giraldo Cifuentes, \\ Prosthodontics Department \\ - Director, Fundación \\ Universitaria CIEO - UNICIEO \\ Address: Bogotá, Colombia \\ Carrera 5-118-10 \\ Máster de Láser en Odontología \\ (EMDOLA) \\ Universitat de Barcelona. \\ Tel: (+57) 3153433898 \\ Email: \\ h.giraldo@unicieo.edu.co
}

Published online October 3 2020

\begin{abstract}
Introduction: The objective of this study was to compare in vitro the resistance and type of failure in the debonding of lithium disilicate veneers with four different thicknesses using an erbium chromium yttrium-scandium gallium-garnet (Er,Cr:YSGG) laser.

Methods: Sixty-eight bovine teeth were used to bond round lithium disilicate veneers with a 6-millimeter diameter and four different thicknesses: group $1(0.4 \mathrm{~mm})$, group $2(0.8 \mathrm{~mm})$, group 3 $(1.2 \mathrm{~mm})$ and group $4(1.6 \mathrm{~mm})$. Each sample was irradiated with an Er,Cr:YSGG laser with $4 \mathrm{~W}$ of power and a frequency of $50 \mathrm{~Hz}$, during 60 seconds, scanning concentrically. The energy density per pulse or fluency applied was $5.33 \mathrm{~J} / \mathrm{cm}^{2}$ for the four groups. The samples were subjected to a force in a universal testing machine and then observed under a microscope to determine the type of failure. Data were statistically analyzed with the non-parametric Kruskal-Wallis test.

Results: The tendency in the results revealed that the thicker veneers showed more resistance to the debonding process. The debonding strength for group 3 was the highest $(5.62 \mathrm{MPa})$, followed by group $4(5.20 \mathrm{MPa})$, then group $2(0.85 \mathrm{MPa})$ and finally group $1(0.0 \mathrm{MPa})$. The most frequent type of failure was cohesive failure in cement (CC) for all groups, with $73.53 \%(P \leq 0.083)$.

Conclusion: $\mathrm{Er}, \mathrm{Cr}$ :YSGG laser irradiation influences the debonding of lithium disilicate veneers with different thicknesses: the smaller thickness showed the greater debonding. The thickness of veneers was not associated with the type of failure.

Keywords: Dental debonding; Er,Cr:YSGG laser; Dental veneers; Lithium disilicate; Thickness.
\end{abstract}

\begin{abstract}
Introduction
Ceramic veneers have become an alternative in restorative dentistry. One material used for their fabrication is lithium disilicate, which, due to its high mechanical and aesthetic properties, provides patients with a reliable treatment alternative ${ }^{1-3}$ Lithium disilicate is indicated $\mathrm{f}$ or usage in restoration types like inlays, onlays, veneers, full crowns and anterior fixed prostheses up to three units. ${ }^{4}$ Depending on the treatment of choice, the thickness may vary between 0.3 and $1.3 \mathrm{~mm}$ for veneers and 1.0 to $1.5 \mathrm{~mm}$ for crowns. ${ }^{5}$ In treatments with veneers, it is possible to find undesirable effects after cementation, such as sensitivity, secondary caries, color changes and microfiltration; in some of these cases, it is necessary to remove the restoration. ${ }^{6}$ One method for the removal of free metal restorations is the use of an Er,Cr:YSGG laser. This laser emits with a wavelength of $2780 \mathrm{~nm}$, which is absorbed by the hydroxyapatite crystals present in dental hard tissues and by the water present in the soft tissues. Thus, this type of laser is indicated for cutting and preparing hard tissues,
\end{abstract}

avoiding the photothermic effect through a cooling process using air and water pulverization. Previous studies have shown that the debonding of veneers using the conventional method with drills causes fractures and may affect the dental structure because it is not easy to differentiate the veneer from the resin cement and the dental structure. ${ }^{7}$ The use of a laser for dental restoration will produce a thermal softening effect, thermal ablation or photoablation of the resinous cement. These effects will favor debonding and depending on the integrity of the veneers, these may be recovered and reused, reducing costs and operational time. However, the thermal ablation effect or photoablation must not cause damage to dental tissue, pulp and restorations. ${ }^{8}$ There is limited scientific evidence about the use of an Er,Cr:YSGG laser in the debonding of lithium disilicate veneers with different thicknesses. ${ }^{7}$ In consequence, the objective of this study was to compare the resistance and type of failure in the debonding of lithium disilicate veneers with four different thicknesses after the use of an Er,Cr:YSGG laser. 


\section{Materials and Methods}

After the approval of the Ethics Committee of Fundación Universitaria UniCIEO, 68 bovine incisor teeth of with no crown fractures, enamel defects or caries were used. They were stored in distilled water at a temperature of $4^{\circ} \mathrm{C}$ for less than 6 months. The organic residues were removed with water steam, and the coronal surface was cleaned with a prophylaxis brush and baking soda for 10 seconds and washed with distilled water for 30 seconds. Crowns were cut at the cementoenamel junction with a carbide disk, and pulp tissue was removed.

The labial surface of the teeth was prepared with a 22-FG84714 ${ }^{\circledR}$ medium-grain diamond milling cutter (Jota, Rüthi, Switzerland) and with a handpiece at 40000 rpm with water. Enamel milling was made in an incisocervical direction. Each sample was put in an square aluminum support of side $2.5 \mathrm{~cm}$ and 1 centimeter in height. Specimens were immersed in Flow Stone ${ }^{\circledR}$ type IV plaster (Whip Mix, Kentucky, USA) leaving the labial face exposed in the preparation area. Finally, the excess stone was removed from each specimen with fine grain sandpaper.

Six-millimeter diameter plastic anesthesia tubes were filled with microparticle resin Patten Resin ${ }^{\circledR}$ (GC Europe, Kortrijk, Belgium) to obtain five resin sticks. Bellavest $\mathrm{T}^{\circledR}$ (BEGO, Bremen, Germany) was used in order to invest the sticks. A silicone ring was placed in a Miditherm ${ }^{\circledR}$ 100 wax evaporation oven (BEGO, Bremen, Germany). Subsequently, IPS e.max-Press ${ }^{\circledR}$ LT A1 lithium disilicate tablets (Ivoclar Vivadent, Schaan, Liechtenstein) were placed in an injection oven (EP $600 \mathrm{Combi}^{\circledR}$ Ivoclar Vivadent, Liechtenstein) at a temperature of $920^{\circ} \mathrm{C}$ for 30 minutes.

After ceramic sticks were recovered, they were sandblasted with glass pearls at a pressure of 4 bars. Lithium disilicate sticks were placed in a plastic container with IPS e.max Press Invex Liquid ${ }^{\circledR}$ hydrofluoric acid solution (Ivoclar Vivadent, Schaan, Liechtenstein) on an In-Ceram Vitasonic II $^{\circledR}$ ultrasound unit (VITA, Bad Säckingen, Germany) for 15 minutes. The veneers were cut with a diamond disc, calibrated and divided into four groups according to their thickness: $0.4,0.8,1.2$ and 1.6 millimeters. Each group consisted of 17 round laminates of a 6-mm diameter. Two precision calipers were used for this purpose. Bonding was achieved through prophylaxis with baking soda and a posterior total enamel etching with $37 \%$ Superetch ${ }^{\circledR}$ orthophosphoric acid (SDI, Victoria, Australia) for 10 seconds. The samples were then washed and the adhesive system Tetric-N Bond Universal ${ }^{\circledR}$ (Ivoclar Vivadent, Schaan, Liechtenstein) was applied to the enamel surface. The veneers were handed with OptraStick ${ }^{\circledR}$ applicators (Ivoclar Vivadent, Schaan, Liechtenstein) and etched with 5\% IPS Ceramic ${ }^{\circledR}$ hydrofluoric acid (Ivoclar Vivadent, Schaan, Liechtenstein) for 20 seconds. Then, they were washed, wrapped in cotton, placed for 1 minute on an In-Ceram Vitasonic II ${ }^{\circledR}$ ultrasound unit (VITA, Bad
Säckingen, Germany), dried with air and silanized with Monobond $\mathrm{N}^{\circledR}$ (Ivoclar Vivadent, Schaan - Liechtenstein) for 180 seconds. The veneers were bonded with Variolink Esthetic $^{\circledR}$ N LC light curing cement (Ivoclar Vivadent, Schaan, Liechtenstein). Afterwards, they were placed on the specimens by manual pressure and excess material was removed. Light curing was performed for 40 seconds in a ramp mode, from 500 to $1200 \mathrm{~mW} / \mathrm{cm}^{2}$, with the light curing device Bluephase ${ }^{\circledR}$ (Ivoclar Vivadent, Schaan, Liechtenstein) at a distance of $5 \mathrm{~mm}$.

Irradiation was performed with a Waterlase $\mathrm{MD}^{\circledR}$ Er,Cr:YSGG laser (Biolase - Irvine, USA), previously calibrated with a Gentec ${ }^{\circledR}$ external power meter (EO Maestro, Canada). The Turbo ${ }^{\circledR}$ handpiece was measured with an MX7 sapphire tip, and the radiation beam was measured at the exit of the fiber with a Mitutoyo ${ }^{\circledR}$ digital calibrator (Vernier, Japan) using thermal paper, measuring a diameter of $1.4 \mathrm{~mm}$. A device was used to maintain perpendicularity and the 4 -mm distance of the radiation beam. The irradiation parameters are shown in Table 1.

The samples were placed in an Instron ${ }^{\circledR} 3366$ universal testing machine (Instron Corp, Norwood, USA). A force was applied to the interface of the tooth laminate at a speed of $1.5 \mathrm{~mm}$ per minute. The data were collected in storage tables and the necessary conversions were applied to express the results in megapascals $(\mathrm{MPa})$, taking into account the following formula:

Laminate area: $\pi \cdot \mathrm{r}^{2}=28.27 \mathrm{~mm}^{2}$

$\mathrm{N} / 28.27=$ Value in $\mathrm{MPa}$

To determine the type of failure, a Stemi $2000 C^{\circledR}$ microscope (Zeiss, Oberkochen, Germany) was used, and each sample was observed at $8 \mathrm{X}$ magnification.

Table 1. Irradiation Parameters With the Er,Cr:YSGG Laser

\begin{tabular}{ll}
\hline Type of laser & Er,Cr:YSGG \\
\hline Emission mode & Pulsed "H" mode \\
\hline Pulse duration & 140 microseconds \\
\hline Energy distribution & Spiral mode \\
\hline Peak power & $571.43 \mathrm{~W}$ \\
\hline Average power & $4 \mathrm{Watts}$ \\
\hline Spot diameter at focus & $1.4 \mathrm{~mm}$ \\
\hline Focus spot area & $0.01539 \mathrm{~cm}^{2}$ \\
\hline Spot diameter at tissue & $1.4 \mathrm{~mm}$ \\
\hline Focus-to-tissue & $4 \mathrm{~mm}$ \\
\hline Spot area at tissue & $0.2827 \mathrm{~cm}^{2}$ \\
\hline Fluence & $5.33 \mathrm{~J} / \mathrm{cm}^{2}$ \\
\hline Peak power density at spot area & $37130 \mathrm{~W} / \mathrm{cm}^{2}$ \\
\hline Peak power density at tissue & $2021.33 \mathrm{~W} / \mathrm{cm}^{2}$ \\
\hline Average power density at spot area & $260 \mathrm{~W} / \mathrm{cm}^{2}$ \\
\hline Average power density at tissue & $14.15 \mathrm{~W} / \mathrm{cm}^{2}$ \\
\hline Beam divergence & Perpendicular \\
\hline Water irrigation & $20 \%$ \\
\hline Air and aspirating airflow & $20 \%$ \\
\hline
\end{tabular}


Photographs of all samples were taken with an AxioCam ${ }^{\circledR}$ ERc5s (Zeiss, Oberkochen, Germany) digital camera and stored in a digital folder using ZEN Lite ${ }^{\circledR}$ Software (Zeiss, Oberkochen, Germany). Shear force values and type of failure were analyzed: type 1) enamel adhesive (AE), type 2) cohesive in cement (CC), type 3) lithium disilicate adhesive (AD), and type 4) cohesive in lithium disilicate (CD).

Considering the abnormal distribution of the data, a non-parametric Kruskal-Wallis test with a 95\% confidence interval was used with Minitab 19 software to determine the effect of the sample thickness on resistance. Because of the $P$ value of 0.083 considered not significant for the type of failure, the analysis was performed using contingency tables.

\section{Results}

In group $1(0.4 \mathrm{~mm}), 64.705 \%$ of the veneers were debonded only with the laser; in groups $2(0.8 \mathrm{~mm})$ and $3(1.2 \mathrm{~mm})$, this value was $47.058 \%$; and in group 4 (1.6 $\mathrm{mm}$ ), this value was $29.411 \%$. Fifty-three percent of the veneers irradiated with the laser that did not debond were subjected to a force in the Instron ${ }^{\circledR}$ universal testing machine (Table 2).

An abnormal distribution of the data was present, for which a Kruskal-Wallis test was performed, with $P$ value $=0.083$ (Table 3 ).

The results show that the resistance to debonding tends to be proportional to the thickness of the veneers. The least variability in the data corresponds to group 1 ( 0.4 $\mathrm{mm})$ and the greatest variability to group $3(1.2 \mathrm{~mm})$ (Figure 1).

The type of failure that occurred most frequently in the veneers debonded only with laser irradiation and the veneers irradiated and subsequently placed in the Instron ${ }^{\circledR}$ machine for their debonding was type 2 failure (CC), at $73.53 \%$ in the four thickness groups (Figure 2).

\section{Discussion}

In this study, the effect of irradiation with an Er,Cr:YSGG laser on the debonding of lithium disilicate veneers was observed, evaluating the resistance to debonding and the type of failure in veneers with four different thicknesses. Multiple studies have evaluated the use of lasers to promote the debonding of restorative materials. ${ }^{9-13}$

Morford et al evaluated the debonding of veneers with an Er:YAG laser, aiming to determine that the use of the laser was effective through the ablation process that occurs
Table 3. Kruskal-Wallis Test: Stress in MPa With Respect to Thickness

\begin{tabular}{lllll}
\hline Descriptive Statistics & & & & \\
\hline Thickness & $\mathbf{N}$ & Median & Mean Rank & Z Value \\
\hline 1 & 17 & 0.000 & 25 & -2.28 \\
2 & 17 & 0.852 & 34.7 & 0.05 \\
3 & 17 & 5.615 & 37.5 & 0.73 \\
4 & 17 & 5.199 & 40.7 & 1.50 \\
Overall & 68 & & 34.5 & \\
\hline Test & & & & \\
\hline Null hypothesis & & $\mathrm{H}_{0}$ All medians are equal & \\
Alternative hypothesis & & $\mathrm{H}_{1:}$ At least one median is different \\
\hline Method & DF & H Value & $\boldsymbol{P}$ Value \\
\hline Not adjusted for ties & & 3 & 5.99 & 0.112 \\
Adjusted for ties & & 3 & 6.69 & 0.083 \\
\hline
\end{tabular}

at the interface between the veneer and cement, without damaging the tooth or the dental pulp. These authors conclude that the use of the laser in these cases results in a safe method for the dental structure, using laminate thicknesses of $1.26 \mathrm{~mm} \pm 0.04 \mathrm{~mm}$ and irradiating with $4 \mathrm{~J} / \mathrm{cm}^{2}$ fluence. ${ }^{10}$ One of the thicknesses as well as the fluence used in the present study were similar and can be considered safe for the tooth after irradiation with the laser.

One factor that can influence the effect of the laser on the debonding of veneers is the choice of cement. In this study, a resin cement of light curing without tertiary amines was used, resulting in an ablative effect on the cement that is generated by irradiation with the laser. Tak et al, in 2015, evaluated the effect of the Er:YAG laser on the debonding of ceramic veneers with different resin cements, concluding that the process was effective. This phenomenon was explained as an effect of "thermal ablation" and "photoablation" producing hydrodynamic vaporization and ejection of the resin. ${ }^{11}$

In the present study, it was observed that group 1 (0.4 $\mathrm{mm}$ ) showed the greatest debonding only with the use of the laser. This study did not evaluate laser transmission; however, the fabrication material and thickness were similar to those used by Sari et al, who compared the transmission of laser light through different types of ceramic materials: sintered zirconium oxide ceramics, monolithic zirconium oxide ceramics, feldspathic ceramics, leucite-reinforced glass ceramics and lithium disilicate ceramics. Each group had two different thicknesses: 0.5 and $1 \mathrm{~mm}$. The results showed significant

Table 2. Number and Percentage of Veneers Debonded With the Laser for Each Thickness Group

\begin{tabular}{lccc}
\hline Thickness Group & Number of Veneers & Number of Veneers Debonded With Laser & Percentage of Veneers Debonded With Laser \\
\hline 1 & 17 & 11 & $64.705 \%$ \\
2 & 17 & 8 & $47.058 \%$ \\
3 & 17 & 8 & $47.058 \%$ \\
4 & 17 & 5 & $29.411 \%$ \\
\hline
\end{tabular}




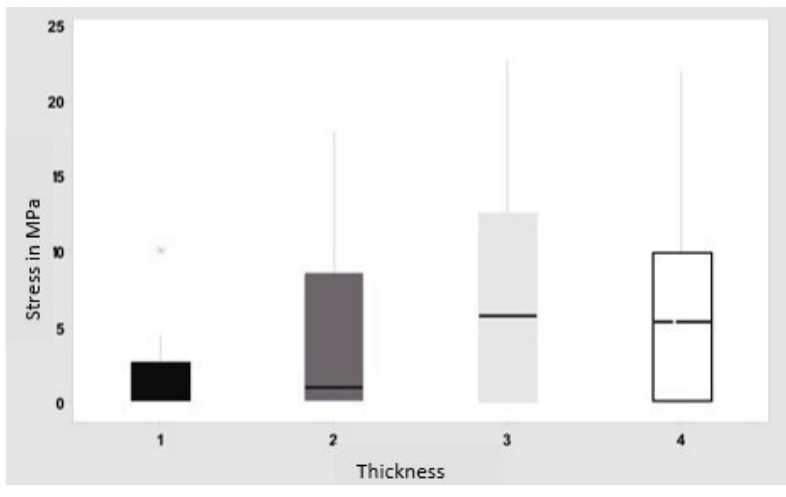

Figure 1. Thickness Data Dispersion With Respect to Stress in MPa.

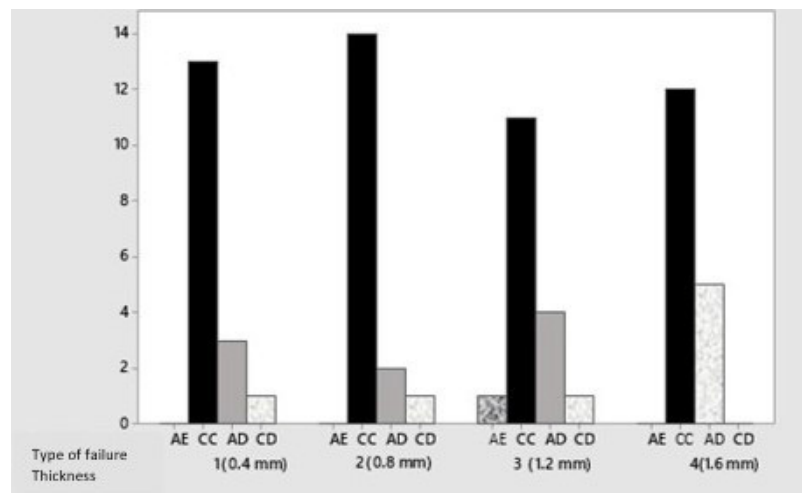

Figure 2. Distribution of the Number of Laser-Irradiated Veneers by the Thickness Group According to the Type of Failure. differences among the different materials, obtaining the highest laser transmission in lithium disilicate ceramics with a thickness of $0.5 \mathrm{~mm}(88 \%){ }^{12}$

In this study, laser irradiation of lithium disilicate veneers was performed for 60 seconds with 4-Watt power. These parameters were the same as those used by Gurney et al, who used an Er,Cr:YSGG laser, with the aim of determining the most effective power and exposure time for the removal of lithium disilicate veneers. They determined that using 3.5 and 4 Watts of power over 60 seconds, the veneers could be removed without producing pulp damage. ${ }^{13}$

There is enough literature supporting the histological similarity between bovine teeth and human teeth. ${ }^{14-16}$ This protocol is suggested for management of the debonding of veneers with different thicknesses in clinical practice using an Er,Cr:YSGG laser.

Other authors have used Er,Cr:YSGG lasers with fluences similar to those of the present study and directly on the enamel during the preparation of cavities, concluding that the temperature of the irradiation in similar conditions does not affect the pulp tissue. ${ }^{17}$

The most recent researches on the debonding of ceramic veneers use erbium lasers ${ }^{18-23}$ and fewer studies are known about other types of lasers being used to debond ceramic veneers, such as $\mathrm{CO}_{2}$ and diode lasers. ${ }^{24,25}$

\section{Conclusion}

1. The thickness of lithium disilicate veneers influences its debonding resistance. When using the Er,Cr:YSGG laser for the irradiation to lower thickness veneers, the resistance to debonding is lower too.

2. The type of failure is not associated with the thickness of lithium disilicate veneers when they are irradiated with the Er,Cr:YSGG laser. The cohesive failure in the cementing agent was the most frequent type of failure..

\section{Conflict of Interests}

The authors declare no conflict of interest.

\section{Acknowledgement}

The authors thank the laser department and the biomaterials laboratory of UniCIEO University, as they made this study possible.

\section{References}

1. Ritter RG. Multifunctional uses of a novel ceramic-lithium disilicate. J Esthet Restor Dent. 2010;22(5):332-41. doi: 10.1111/j.1708-8240.2010.00362.x.

2. Spear F, Holloway J. Which all-ceramic system is optimal for anterior esthetics? J Am Dent Assoc. 2008;139 Suppl:19S24S. doi: 10.14219/jada.archive.2008.0358.

3. Kelly JR. Dental ceramics: what is this stuff anyway? J Am Dent Assoc. 2008;139 Suppl:4S-7S. doi: 10.14219/jada. archive.2008.0359.

4. Seydler B, Rues S, Müller D, Schmitter M. In vitro fracture load of monolithic lithium disilicate ceramic molar crowns with different wall thicknesses. Clin Oral Investig. 2014;18(4):1165-1171. doi: 10.1007/s00784-013-1062-8.

5. Brunton PA, Aminian A, Wilson NH. Tooth preparation techniques for porcelain laminate veneers. $\mathrm{Br}$ Dent $\mathrm{J}$. 2000;189(5):260-2. doi: 10.1038/sj.bdj.4800739.

6. Gurel G, Sesma N, Calamita MA, Coachman C, Morimoto S. Influence of enamel preservation on failure rates of porcelain laminate veneers. Int J Periodontics Restorative Dent. 2013;33(1):31-9. doi: 10.11607/prd.1488.

7. Burke FJT. Survival rates for porcelain laminate veneers with special reference to the effect of preparation in dentin: a literature review. J Esthet Restor Dent. 2012;24(4):257-65. doi: 10.1111/j.1708-8240.2012.00517.x.

8. Taşar S, Ulusoy MM, Merıç G. Microshear bond strength according to dentin cleansing methods before recementation. J Adv Prosthodont. 2014;6(2):79-87. doi: 10.4047/jap.2014.6.2.79.

9. Cötert HS, Dündar M, Oztürk B. The effect of various preparation designs on the survival of porcelain laminate veneers. J Adhes Dent. 2009;11(5):405-11.

10. Morford CK, Buu NCH, Rechmann BMT, Finzen FC, Sharma AB, Rechmann P. Er:YAG laser debonding of porcelain veneers. Lasers Surg Med. 2011;43(10):965-74. doi: $10.1002 / \mathrm{lsm} .21144$.

11. Tak O, Sari T, Arslan Malkoç M, Altintas S, Usumez A, Gutknecht N. The effect of transmitted Er:YAG laser 
energy through a dental ceramic on different types of resin cements. Lasers Surg Med. 2015;47(7):602-607. doi: 10.1002/lsm.22394.

12. Sari T, Tuncel I, Usumez A, Gutknecht N. Transmission of Er:YAG laser through different dental ceramics. Photomed Laser Surg. 2014;32(1):37-41. doi: 10.1089/pho.2013.3611.

13. Gurney ML, Sharples SD, Phillips WB, Lee DJ. Using an Er,Cr:YSGG laser to remove lithium disilicate restorations: A pilot study. J Prosthet Dent. 2016;115(1):90-4. doi: 10.1016/j.prosdent.2015.08.003.

14. Nakamichi I, Iwaku M, Fusayama T. Bovine teeth as possible substitutes in the adhesion test. JDent Res.1983;62(10):107681. doi: $10.1177 / 00220345830620101501$.

15. Yassen GH, Platt JA, Hara AT. Bovine teeth as substitute for human teeth in dental research: a review of literature. J Oral Sci. 2011;53(3):273-82. doi: 10.2334/josnusd.53.273.

16. Iseri U, Oztoprak MO, Ozkurt Z, Kazazoglu E, Arun T. Effect of Er:YAG laser on debonding strength of laminate veneers. Eur J Dent. 2014;8(1):58-62. doi: 10.4103/13057456.126243.

17. De Freitas PM, Soares-Geraldo D, Biella-Silva AC, Silva $\mathrm{AV}$, da Silveira BL, Eduardo C de P. Intrapulpal temperature variation during Er,Cr:YSGG enamel irradiation on caries prevention. J Appl Oral Sci. 2008;16(2):95-99. doi: 10.1590/ s1678-77572008000200003.

18. Ghazanfari R, Azimi N, Nokhbatolfoghahaei H, Alikhasi M. Laser aided ceramic restoration removal: A comprehensive review. J Lasers Med Sci. 2019;10(2), 86-91. doi: 10.15171/ jlms.2019.14.

19. Alikhasi M, Monzavi A, Ebrahimi H, Pirmoradian M,
Shamshiri, A, Ghazanfari R. Debonding time and dental pulp temperature with the Er,Cr:YSGG laser for debonding feldespathic and lithium disilicate veneers. J Lasers Med Sci. 2019;10(3):211-214. doi: 10.15171/jlms.2019.34.

20. AlBalkhi M, Swed E, Hamadah O. Efficiency of Er:YAG laser in debonding of porcelain laminate veneers by contact and non-contact laser application modes (in vitro study). J Esthet Restor Dent. 2018;30(3):223-228. doi: 10.1111/ jerd.12361.

21. Khoroushi M, Kachuie M. Prevention and Treatment of White Spot Lesions in Orthodontic Patients. Contemp Clin Dent. 2017;8(1):11-19. doi:10.4103/ccd.ccd_216_17.

22. Karagoz-Yildirak M, Gozneli R. Evaluation of rebonding strengths of leucite and lithium disilicate veneers debonded with an Er:YAG laser. Lasers Med Sci. 2020;35:853-60. doi: 10.1007/s10103-019-02872-8.

23. Kellesarian SV, Ros Malignaggi V, Aldosary KM, Javed F. Laser-assisted removal of all ceramic fixed dental prostheses: A comprehensive review. J Esthet Restor Dent. 2018;30(3):216-222. doi: 10.1111/jerd.12360.

24. Romano FL, Pessoti G, Galo R, Gomes-Silva JM, Lucisano $\mathrm{MP}$, Borsatto $\mathrm{MC}$, et al. Does the $\mathrm{CO}_{2}$ laser reduce bond strength in different types of ceramic brackets? Dental Press J Orthod. 2017;22(2):55-60. doi: 10.1590/21776709.22.2.055-060.oar.

25. Stein S, Kleye A, Schauseil M, Hellak A, KorbmacherSteiner H, Braun A. 445-nm diode laser-assisted debonding of self-ligating ceramic brackets. Biomed Tech (Berl). 2017;62(5):513-520. doi: 10.1515/bmt-2016-0027. 